\title{
Clinical Training Stress Inducing Factors among Intern Nurses in Neonatal Intensive Care Unit
}

\author{
Abeer Abd-El-Razik Ahmed, Lecturer \\ Pediatric Nursing, Faculty of Nursing, Alexandria University \\ Gehan Maher Khamis, Lecturer \\ Pediatric Nursing, Faculty of Nursing, Alexandria University
}

\begin{abstract}
Improving the quality of clinical training among intern nurses (INs) requires provision of suitable educational environment and one of its requirements is determination of the stressinducing factors. Objective: To identify the clinical training stress inducing factors among INs in neonatal intensive care unit (NICU). Setting: The study was carried out in NICU at El-Shatby Maternity University Hospital, Alexandria University. Subjects: The subjects of present study comprised of 140 INs providing care for neonates admitted to NICU. Tools: Three tools were used to collect necessary data, namely, Characteristics of INs Structured Interview Schedule, Perceived Stress Scale (PSS-10) and Intern Nurses' Stress Factors Structured Questionnaire. Results: The study revealed that more than half (52.1\%) of INs had moderate stress level. Discrepancy between theory and practice was the most perceived academic stress factor among the majority of INs (90.0\%). While, public opinion about nurses was the most perceived personal stress factor among 98.6\% of INs. Moreover, criticism by preceptor was the most perceived interpersonal stress factor. Furthermore, providing care for many neonates at the same time was the most clinical stress factor among INs in NICU. Conclusion: It can be concluded that INs are confronted with multiple stress factors such as, academic, personal, interpersonal, clinical, environmental, and health care system. Recommendations: The main recommendation of current study was collaboration between health care institutions and preceptors should be assured in order to overcome stress inducing factors in NICU.
\end{abstract}

Keywords: Clinical training, Stress inducing factors, Intern nurses, Neonatal intensive care.

\section{Introduction}

Stress is a universal experience and a frequent component throughout life ${ }^{(1)}$. It is the response of the body to either internal or external stimuli which are called stressors. Those stressors refer to any events in which environmental or internal needs or both are more than the individual coping resources ${ }^{(2)}$. Stress can negatively affect any individual as it may lead to distress and emotional disturbance $^{(3)}$. It is well documented that working in high complex specialties such as intensive care units can be a very stressful experience $^{(4)}$.
Stress is recognized as an inherent feature of nurses' work, and growing evidence suggests that it may increase in severity ${ }^{(5)}$. Among all staff members, Intern Nurses (INs) are responsible for the majority of everyday care of neonates during their clinical training in Neonatal Intensive Care Unit (NICU) ${ }^{(6)}$. During the internship year, they gain practices in a real world setting under the guidance of experienced supervisors. This year helps INs develop their management competencies as clinical decision making, planning, communication, critical thinking, and caring ${ }^{(7)}$. However, they are prone to 
stress during this transitional nature of their life to them, this period is a turning point from student nurse to professional nurse practicing in a hospital. It was reported that perceived stress level is high among INs due to many stressors ${ }^{(8)}$.

Stress can be of outmost importance in $\mathrm{NICU}^{(4)}$. In general, the most sources of stress is workload, inadequate staff, time pressure, relationship with other clinical staff, poor locus of control, poor group cohesion, lack of adequate supervisory support, coping with emotional needs of neonates and their parents, poor diagnosis, interpersonal conflict, death and dying ${ }^{(9)}$. Singh et. al $(2011)^{(10)}$ mentioned that INs experience stress from multiple sources in NICU as lack of experience, discomfort at being evaluated by faculty members and fear of making mistakes. Pati et. al $(2008)^{(11)}$ also added that, enclosed atmosphere, excessive noise, unpleasant sights and sounds are also considered as sources of stress. Work stress increases because INs face growing numbers of critically ill neonates and endure pressure to conform to the rigorous standards of costcontainment and quality assurance programs $^{(12)}$. In addition, INs are challenged by rapidly changing environment and are confronted by the demand for technologic excellence $^{(9)}$. Lack of professional recognition and the underestimation of nurse's skills and qualifications by other health professionals, especially doctors is another source of stress ${ }^{(13)}$. Besides, NICU are different from adult intensive care units in nature. Highly vulnerable neonates and their specific developmental needs are unique features of care in $\mathrm{NICU}^{(2)}$. These sources in combination with the organizational constraints inherent in the hospital system expose the INs to more amount of work-related stress ${ }^{(14)}$. Basically, the stress among them can be divided into six categories, which are academic, personal, interpersonal, clinical, environmental, and health care system stress factors $^{(15)}$.
It is important to examine the nature of stress experienced by INs because excessive and unrelieved stress may influence job satisfaction and contribute to turnover. In addition, the end result of continues work stress over time is worker burnout, which may lead to serious physical and emotional problems ${ }^{(16)}$. Moreover, this tension during clinical training might have negative effects on students learning and success. Furthermore, stress of nurses is one of the factors reducing the quality of care and increasing neonatal morbidity and mortality rates ${ }^{(17)}$.

One of the main goals of the third millennium is to reduce mortality rate among neonates. Factors enhancing service quality would obviously reduce mortality. Since human resources can affect service quality, identifying current situation and planning strategies to eliminate stressors can definitely maximize the efficiency of human resources and thus the quality of nursing services ${ }^{(18)}$. Therefore, it was necessary to conduct this research to highlight clinical training stress in NICU from the perspective of intern nurses.

\section{Aim of the Study}

This study aimed to identify the clinical training stress inducing factors among intern nurses in neonatal intensive care unit.

\section{Research Question:}

What are the clinical training stress inducing factors among intern nurses in the neonatal intensive care unit?

\section{Materials and Method}

\section{Materials}

Design: A descriptive design was used to accomplish this study.

Setting: This study was carried out at the NICU of EL-Shatby Maternity University Hospital in Alexandria. 
Subjects: All INs who practiced neonatal care in NICU at the previously mentioned setting for at least one month during their internship year 2014-2015 comprised the subjects. There number was 140 students.

Tools: Three tools were used to collect necessary data:

\section{Tool I: Characteristics of Intern Nurses Structured Interview Schedule}

This tool was developed by the researcher to collect the necessary data. It included age, sex, marital status, work schedule, experience in private NICU and residence.

\section{Tool II: Perceived Stress Scale (PSS-10)}

This scale was developed by Cohen et.al $(1983)^{(19)}$ to measure stress level among nursing students based on their feelings and thoughts. It included 10 items. Responses to this scale were scored by using 5-point Likert type scale ranged from 0 to 4 as follows:

- Never stressful (0)

- Almost never stressful (1)

- Sometimes stressful (2)

- Fairly often stressful (3)

- Very often stressful (4)

The total score ranged from 0-40. The total score of PSS-10 was ranked as follows:

- Zero to 20 indicated mild stress.

- 21 to 30 indicated moderate stress.

- 31 to 40 indicated high stress.

\section{Tool III: Intern Nurses' Stressors} Structured Questionnaire

It was developed by the researcher after thorough reviewing of related literature ${ }^{(9,10)}$ to assess the INs' stressors in NICU. It included six dimensions of stress factors experienced by INs namely: academic (10 items), personal (10 items), interpersonal (10 items), health care system (10 items), clinical (10 items) and environmental (10 items). Responses to these stress factors were scored by using 4-point Likert type scale ranged from 0 to 3 as follows:

- None stress (0)

- Little stress (1)

- Moderate stress (2)

- High stress (3)

The total score ranged from $0-180$ and was ranked as follows:

- Zero to 90 indicated mild stress.

- 91 to 135 indicated moderate stress.

- 136 to 180 indicated high stress.

\section{Method}

- An official approval for conducting the study was obtained from the director of El-Shatby Maternity University Hospital in Alexandria to facilitate the research implementation.

- Tool I was developed by the researcher.

- Reliability of Tool II was estimated using the Cronbach's Coefficient alpha test which was 0.85 .

- Tool III was developed by the researcher after thorough review of related literature. It was tested for its content validity by five experts in pediatric nursing field.

- Reliability of tool III was estimated using the Cronbach's Coefficient alpha test which was 0.85 .

- A pilot study was carried out on 14 INs to test the feasibility and clarity of the tools. Accordingly, the necessary modifications were done. Those INs were excluded from the study subjects.

- Every IN was interviewed individually to identify their characteristics and each interview took about 15 minutes. 
- The INs were asked to respond to the Perceived Stress Scale and Intern Nurses' Stressors Questionnaire in nursing office during the break time.

- The data were collected during a period of nine months starting from the beginning of September 2014 till the end of August 2015.

\section{Ethical considerations:}

- Written informed consent from INs for their participation was obtained after explaining the aim of the study.

- Students were ascertained for their data confidentiality, and privacy was considered.

- Students had the right to withdraw from the study at any time.

\section{Statistical Analysis}

The collected data were coded and transformed into special design formats, so as to be suitable for computer feeding. The Statistical Package for Social Sciences (SPSS version 20) was utilized for data analysis and tabulation. The 0.05 level was used as the cut off value for statistical significance and the following statistical measures were used. Descriptive statistics: count and percentage. The analytical statistics included: the minimum, maximum, arithmetic means, standard deviation, Chi Square test and Fisher's Exact Test.

\section{Results}

Table (1) illustrates characteristics of INs. It was clear from the table that, the age of $87.1 \%$ of INs was more than 20 years old with a mean of $22.24 \pm 2.158$ years. Female nurses constituted $77.9 \%$ of the subjects. It was also clear that, the majority $(90.7 \%)$ of INs were not married. More than three quarters $(77.1 \%)$ of them lived away from clinical training area. Concerning, previous INs years of the experience in private NICU, it was found that more than half
$(59.3 \%)$ of them had no experience. In relation to work schedule, it is obvious that the majority $(88.6 \%)$ of INs were rotating among three shifts.

Intern nurses' stress level according Perceived Stress Scale is presented in table (2). It was revealed that, slightly more than half $(52.1 \%)$ of INs had moderate stress level, while, low proportion (19.3\%) of them had high stress level.

Table (3) shows academic stress factors among INs in NICU. It was observed that, the most perceived academic stress factor among INs was a discrepancy between theory and practice, where $90 \%$ of them perceived it as high academic stress factor. While, none stress perceived among only $10 \%$ of INs regarding the same stress factor. On the other hand, inability to discuss a neonate's illness with preceptors or health personnel was the least perceived academic stress factor reported by $20.7 \%$ of INs as high, $47.2 \%$ moderate, $25.7 \%$ little, and only $6.4 \%$ as none stress factor.

Personal stress factors among INs in NICU are described in table (4). It was apparent that, public opinion about nurses constituted $98.6 \%$ as high personal stress factor and only $1.4 \%$ as moderate among INS. Furthermore, working during night shift constituted $97.1 \%$ and $2.9 \%$ of INs as high and moderate personal stress factor respectively. While, approximately one third $(38.6 \%)$ of INs perceived inability to do daily work as a high personal stress factor and similar percentage $(38.6 \%)$ of them perceived it as a moderate stress factor.

Table (5) represents interpersonal stress factors among INs in NICU. It was clear that, three quarters $(75 \%)$ of INs mentioned that criticism by preceptors and colleagues in front of medical staff was the highest perceived interpersonal stress factor. Meanwhile, only $25 \%$ of them considered it as moderate one. Experiencing peer competition in clinical practice was the least perceived interpersonal stress factor 
reported by $38.6 \%, 34.3 \%, 22.1 \%$, and $5.0 \%$ of INs as high, moderate, little, and none interpersonal stress factor respectively.

Health care system stress factors among INs in NICU are portrayed in table (6). It was found that, inadequate staff member working at NICU was the most perceived health care system stress factor mentioned by $88.6 \%$ of INs. While, only $11.4 \%$ of them perceived it as none stress factor. Meanwhile, lack of communication and support from administrators was the least health care system stress factor reported by $39.3 \%$ of INs as high stress factor and $6.4 \%$ of them as none stress factor.

Table (7) explains clinical stress factors among INs in NICU. It was observed that, providing care for many neonates at the same time, fear from transmission of contagious diseases, and providing nursing care to critically ill neonates were reported by the majority of INs $(96.4 \%, 95.0 \%$ and $90.0 \%$ respectively) as high clinical stress factors and perceived as moderate stress factors by the minority of them $(3.6 \%, 5.0 \%$ and $10.0 \%$ respectively). On contrary, too many non-nursing tasks as clerical work was the least perceived clinical stress factor reported by $42.1 \%, 33.7 \%, 19.3 \%$, and $5.0 \%$ of INs as high, moderate, little, and none clinical stress factor respectively.

Environmental stress factors among INs in NICU are demonstrated in table (8). It was noticed that, the most environmental stress factor reported by INs was being exposed to health hazards as radiation as $95 \%$ of them perceived it as high stress factor, $2.9 \%$ as moderate, and $2.1 \%$ as little environmental stress factor. On the other hand, large number of personnel working in NICU was the least perceived environmental stress factor by INs as it was reported by $37.9 \%$ as high, $35.7 \%$ as moderate, $18.6 \%$ as little, and only $7.8 \%$ as none stress factor among INs in NICU.

Table (9) views the relationship betweencharacteristics of INs and their level of stress. It was noted that, a statistical significant relation was found between INs' stress level and their sex $(\mathrm{P}=0.001)$ as approximately one quarter $(24.8 \%)$ of female INs had high stress level compared to none stress among male INs. The displayed findings also revealed that, more than half $(53.8 \%)$ of married INs had high stress level compared to only $15.7 \%$ of single INs. There was a statistical significant relation between marital status and level of stress $(\mathrm{P}=0.001)$. In addition, this table shows that more than one quarter (27.7\%) of INs who had no previous experience in private NICU had high stress level compared to only $7 \%$ of those who had previous experience and the difference was statistically significant $(\mathrm{P}=0.010)$

\section{Discussion}

Nursing students are exposed to stresses emanated from theoretical education settings as well as those coming from clinical training. Clinical training is a vital part of curriculum and plays a crucial role in shaping the basic skills and professional capabilities among the nursing students ${ }^{(20,21)}$. The aim of clinical training is to provide opportunities for students to link their theoretical information with scientific facts. Generally, it is believed that students' nurses are confronted with a lot of stressors during their education ${ }^{(21,22)}$. Clinical training is a complicated process which is affected by several factors. The first step towards promoting quality consists of knowing clinical training stressors, especially with regard to the negative effect of stress on the educational progress of students and subsequently disturbance in their psychophysiological balance ${ }^{(23,24)}$.

Existence of a high level of stress during the clinical training might have a negative effect on student's clinical learning and success. The current study revealed that, slightly more than half of INs experienced moderate level of stress. This could be attributed to the fact that INs are not interested in clinical training as well as absence of ample access to clinical 
preceptors. Moreover, this may also be due to being exposed to an unfamiliar environment. Demands of making new social groups apart from academic pressure and clinical training could also be a reason. This finding is in agreement with the findings of another study conducted by Singh et al. $(2011)^{(10)}$.

The theory-practice gap is a common challenge encountering the new graduate. The findings of the current study reflected that a discrepancy between theory and practice was the most perceived academic stress among INs. This could be due to the transitional nature of college life from classroom to clinical settings. This is in line with Taghavi Larijani et al. $(2007)^{(25)}$ who reported that incompetent professional knowledge after graduation and discordance between theory and clinical education were the most sources of stress among INs.

The present study revealed that the most perceived personal stress factors among INs were public opinion about nurses as well as working during the night shift. These could be justified by ambiguous view of nursing profession by the Egyptian society. Culture wise, having night shift duties is not accepted particularly among females. Similar findings were reported by Chang and Hancock (2003) ${ }^{(26)}$.

The role of the clinical preceptor in making appropriate communication is paramount to create a friendly and supportive environment for INs. The findings of the present study reflected that criticism by preceptors and colleagues in front of medical staff was a high interpersonal stress factor among INs. This could be explained by the fact that most of the study subjects were females who are very sensitive by nature than males. In addition, all of the study subjects were adolescents who are known to be also very sensitive, angry and feel embarrassed from few comments. This is in harmony with Yazdankhah Fard et al. (2009) $)^{(27)}$ who reported that most stressful interpersonal stress factor was teacher's notification in front of personnel and physicians.

It is well known that inadequate staffing in the NICU produces several stressors among health personnel. This appears in the current findings where inadequate staff was the most perceived health care system stress factor among INs. This could be related to the fact that inadequate staffing lead to increase workload and responsibilities of INs which in turn increase their irritability and exhaustion. All these stimuli provoke feelings such as insufficiency and insecurity which will simply impact INs' practices negatively and affect greatly their performance.

One of the Challenges facing INs when dealing with critically ill neonates is to achieve a balance between ensuring safe practice and preventing complications. Findings of the current study revealed that providing care for many neonates and providing care for critically ill neonates were the most perceived clinical stress among INs. This could be attributed to shortage of staff and worsen state of neonates that in turn increase stress level. This finding is supported by Taghavi Larijani et al. (2007) ${ }^{(25)}$ who reported that caring for terminally ill neonates was the most source of stress among students.

Certainly, unpleasant feelings of the "concern with infectious disease transmission" can negatively create stress for INs. One of the highest clinical tensioninducing level in the current study was fear from transmission of contagious diseases. from intern's point of view. This is congruent with the study done by Taghavi Larijani et al. (2007) $)^{(25)}$ and Yazdankhah Fard et al. (2009) ${ }^{(27)}$. Similarly, other studies examining stress-inducing situations at the first clinical experience for operating room students revealed that, fear of affliction with diseases like AIDS and hepatitis has been announced as one of the tension inducing factors at the clinical settings ${ }^{(20,28)}$. One of the reasons for such 
results could be attributed to INs' awareness of transmission ways of contagious diseases and the manner of preventing them which can be taught to them thoroughly during the undergraduate years. Similar finding was reported by Golrokh et al. (2013) ${ }^{(29)}$.

Designing of NICU, spaces, lighting, atmosphere, sounds, and other environmental factors should be strictly considered to prevent stress, exhaustion, and tendency to leave work ${ }^{(18)}$. Based on results of the current study, many environmental stress factors such as available spaces, lighting, atmosphere and noise are proved to be potential causes of stress among INs. This could be justified by the design of NICU that has its own specifications, developed technology, and special physical design and equipment which should meet standard criteria. Similar findings were reported by Valizadeh et al. $(2012)^{(18)}$. Furthermore, according to Morrison et al. $(2003)^{(30)}$ the physical aspects of work such as sudden noise arising from the used equipment in the unit is one of the environmental stressors for nurses.

The present study reported showed that statistical significant relations were found between INs' stress level and their sex and marital status as approximately one quarter of female INs had high stress level compared to none stress level among male INs. In addition, more than half of married INs had high stress level compared to minority of single INs. These findings may be attributed to the fact that females by nature are highly emotional affected than males. Moreover, female INs also, carry out multiple roles at the same time like their role as a wife, a mother, as well as a nurse. In addition, the present study showed significant relation between INs' stress level and their previous experience in private NICU. Where, the INs who had many years of clinical experience may know more than those who had no experience and became familiar with working in NICU and accustomed the special nature of this stress induced place. These findings are inconsistent with Mohammed et al. $(2011)^{(12)}$ who found that there were statistical significant relations between nurses' stress level and their age, unit, and work schedule.

\section{Conclusion}

In the light of the current study, it can be concluded that INs are confronted with various stress factors namely, academic, personal, interpersonal, health care system, clinical, and environmental. Furthermore, there were statistical significant relations between INs' stress level and their sex, marital status, and previous experience in private NICU.

\section{Recommendations}

The following recommendations are suggested:

- Stress management and positive coping strategies regarding clinical training should be incorporated in students' curriculum.

- Preceptors should move towards solving and reducing clinical training stress inducing factors via appropriate stress adaptive strategies and proper communication.

- Collaboration between health care institutions and preceptors should be assured in order to overcome clinical training stress inducing factors in NICU. 
Table (1): Characteristics of Intern Nurses

\begin{tabular}{|c|c|c|}
\hline \multirow{2}{*}{ Intern Nurses' Characteristics } & \multicolumn{2}{|c|}{$\mathrm{n}=\mathbf{1 4 0}$} \\
\hline & No & $\%$ \\
\hline \multicolumn{3}{|l|}{ Age in years } \\
\hline - $\leq 20$ & 18 & 12.9 \\
\hline - $>20$ & 122 & 87.1 \\
\hline $\begin{array}{l}\text { Min-Max } \\
\text { Mean } \pm \text { SD }\end{array}$ & \multicolumn{2}{|c|}{$\begin{array}{c}20-33 \\
22.24 \pm 2.158\end{array}$} \\
\hline \multicolumn{3}{|l|}{ Sex } \\
\hline - $\quad$ Male & 31 & 22.1 \\
\hline - Female & 109 & 77.9 \\
\hline \multicolumn{3}{|l|}{ Marital Status } \\
\hline - Single & 127 & 90.7 \\
\hline - $\quad$ Married & 13 & 9.3 \\
\hline \multicolumn{3}{|l|}{ Residence } \\
\hline - Away from clinical training area. & 108 & 77.1 \\
\hline - Near to clinical training area. & 32 & 22.9 \\
\hline \multicolumn{3}{|l|}{ Experience in private NICU* } \\
\hline - Yes & 57 & 40.7 \\
\hline - No & 83 & 59.3 \\
\hline \multicolumn{3}{|l|}{ Work Schedule } \\
\hline - Rotating shift. & 124 & 88.6 \\
\hline - $\quad$ Morning shift. & 16 & 11.4 \\
\hline
\end{tabular}

NICU*: Neonatal Intensive Care Unit

Table (2): Intern Nurses' Stress Level according to Perceived Stress Scale

\begin{tabular}{|c|c|c|c|c|c|}
\hline \multicolumn{6}{|c|}{$\begin{array}{c}\text { Level of Stress } \\
\quad \mathrm{N}=140\end{array}$} \\
\hline \multicolumn{2}{|c|}{$\begin{array}{c}\text { Low } \\
(0-20) \\
\end{array}$} & \multicolumn{2}{|c|}{$\begin{array}{c}\text { Moderate } \\
(21-30)\end{array}$} & \multicolumn{2}{|c|}{$\begin{array}{c}\text { High } \\
(31-40)\end{array}$} \\
\hline No & $\%$ & No & $\%$ & No & $\%$ \\
\hline 40 & $28.6 \%$ & 73 & $52.1 \%$ & 27 & $19.3 \%$ \\
\hline
\end{tabular}


Table (3): Academic Stress Factors among Intern Nurses in Neonatal Intensive Care Unit

\begin{tabular}{|c|c|c|c|c|c|c|c|c|}
\hline \multirow{3}{*}{ Academic Stress Factors } & \multicolumn{8}{|c|}{$n=140$} \\
\hline & \multicolumn{2}{|c|}{ High } & \multicolumn{2}{|c|}{ Moderate } & \multicolumn{2}{|c|}{ Little } & \multicolumn{2}{|c|}{ None } \\
\hline & No & $\%$ & No & $\%$ & No & $\%$ & No & $\%$ \\
\hline Lack of professional knowledge. & 59 & 42.1 & 51 & 36.4 & 24 & 17.1 & 6 & 4.4 \\
\hline Unfamiliar with medical history and terms. & 61 & 43.6 & 43 & 30.7 & 31 & 22.1 & 5 & 3.6 \\
\hline Worry about poor grades. & 93 & 66.4 & 44 & 31.5 & 3 & 2.1 & 0 & 0.0 \\
\hline Discrepancy between theory and practice. & 126 & 90.0 & 0 & 0.0 & 0 & 0.0 & 14 & 10.0 \\
\hline $\begin{array}{l}\text { Inability to discuss a neonate's illness with } \\
\text { preceptors or health personnel. }\end{array}$ & 29 & 20.7 & 66 & 47.2 & 36 & 25.7 & 9 & 6.4 \\
\hline $\begin{array}{l}\text { Difference between preceptor's instructions } \\
\text { and intern nurses' expectations. }\end{array}$ & 70 & 50.0 & 42 & 30.0 & 25 & 17.9 & 3 & 2.1 \\
\hline Preceptors do not evaluate students fairly. & 58 & 41.4 & 40 & 28.6 & 29 & 20.7 & 13 & 9.3 \\
\hline Lack of care and guidance from preceptors. & 53 & 37.9 & 45 & 32.1 & 35 & 25.0 & 7 & 5.0 \\
\hline Struggling to meet own academic standards. & 52 & 37.1 & 38 & 27.2 & 45 & 32.1 & 5 & 3.6 \\
\hline Lack of experience and preparation. & 57 & 40.7 & 41 & 29.3 & 37 & 26.4 & 5 & 3.6 \\
\hline
\end{tabular}

Table (4): Personal Stress Factors among Intern Nurses in Neonatal Intensive Care Unit

\begin{tabular}{|c|c|c|c|c|c|c|c|c|}
\hline \multirow{3}{*}{ Personal Stress Factors } & \multicolumn{8}{|c|}{$\mathrm{n}=140$} \\
\hline & \multicolumn{2}{|c|}{ High } & \multicolumn{2}{|c|}{ Moderate } & \multicolumn{2}{|c|}{ Little } & \multicolumn{2}{|c|}{ None } \\
\hline & No & $\%$ & No & $\%$ & No & $\%$ & No & $\%$ \\
\hline Inability to do daily work. & 54 & 38.6 & 54 & 38.6 & 29 & 20.7 & 3 & 2.1 \\
\hline $\begin{array}{l}\text { Facing crisis at home or in clinical } \\
\text { training. }\end{array}$ & 56 & 40.0 & 46 & 32.9 & 35 & 25.0 & 3 & 2.1 \\
\hline Public opinion about nurses. & 138 & 98.6 & 2 & 1.4 & 0 & 0.0 & 0 & 0.0 \\
\hline Work during night shift. & 136 & 97.1 & 4 & 2.9 & 0 & 0.0 & 0 & 0.0 \\
\hline Difficulties to get vacations. & 65 & 46.4 & 47 & 33.6 & 25 & 17.9 & 3 & 2.1 \\
\hline Financial burdens. & 74 & 52.9 & 38 & 27.1 & 23 & 16.4 & 5 & 3.6 \\
\hline Difficulties to get health insurance. & 58 & 48.6 & 40 & 28.6 & 29 & 20.7 & 13 & 9.3 \\
\hline Lack of leisure time. & 66 & 41.4 & 38 & 27.1 & 33 & 23.7 & 3 & 2.1 \\
\hline Lack of sleep. & 73 & 52.1 & 39 & 27.9 & 28 & 20.0 & 0 & 0.0 \\
\hline Difficulties with transportation. & 67 & 47.9 & 35 & 25.0 & 32 & 22.9 & 6 & 4.2 \\
\hline
\end{tabular}


Table (5): Interpersonal Stress Factors among Intern Nurses in Neonatal Intensive Care Unit

\begin{tabular}{|c|c|c|c|c|c|c|c|c|}
\hline \multirow{3}{*}{ Interpersonal Stress Factors } & \multicolumn{8}{|c|}{$\mathrm{n}=140$} \\
\hline & \multicolumn{2}{|c|}{ High } & \multicolumn{2}{|c|}{ Moderate } & \multicolumn{2}{|c|}{ Little } & \multicolumn{2}{|c|}{ None } \\
\hline & No & $\%$ & No & $\%$ & No & $\%$ & No & $\%$ \\
\hline $\begin{array}{l}\text { Lack of access to clinical } \\
\text { preceptors. }\end{array}$ & 55 & 39.3 & 55 & 39.3 & 23 & 16.4 & 7 & 5.0 \\
\hline $\begin{array}{l}\text { Lack of collaborative workplace } \\
\text { relationships. }\end{array}$ & 59 & 42.1 & 46 & 32.9 & 32 & 22.9 & 3 & 2.1 \\
\hline $\begin{array}{l}\text { Criticism by preceptors and } \\
\text { colleagues in front of medical } \\
\text { staff. }\end{array}$ & 105 & 75.0 & 35 & 25.0 & 0 & 0.0 & 0 & 0.0 \\
\hline $\begin{array}{l}\text { Conflict with supervisors, } \\
\text { colleagues and physicians. }\end{array}$ & 61 & 43.6 & 41 & 29.3 & 31 & 22.1 & 7 & 5.0 \\
\hline $\begin{array}{l}\text { Performing painful procedures for } \\
\text { neonates. }\end{array}$ & 60 & 42.9 & 36 & 25.7 & 37 & 26.4 & 7 & 5.0 \\
\hline $\begin{array}{l}\text { Experiencing peer competition in } \\
\text { clinical practice. }\end{array}$ & 54 & 38.6 & 48 & 34.3 & 31 & 22.1 & 7 & 5.0 \\
\hline $\begin{array}{l}\text { Preceptor's comparison between } \\
\text { students' performance. }\end{array}$ & 61 & 43.6 & 47 & 33.6 & 27 & 19.2 & 5 & 3.6 \\
\hline $\begin{array}{l}\text { Changing from student's role to } \\
\text { nurse's role. }\end{array}$ & 66 & 47.2 & 48 & 34.3 & 23 & 16.4 & 3 & 2.1 \\
\hline Death of a neonate. & 85 & 60.7 & 44 & 31.4 & 11 & 7.9 & 0 & 0.0 \\
\hline $\begin{array}{l}\text { Demands of clinical practice } \\
\text { exceed physical and emotional } \\
\text { endurance. }\end{array}$ & 73 & 52.1 & 39 & 27.9 & 23 & 16.4 & 5 & 3.6 \\
\hline
\end{tabular}

Table (6): Health Care System Stress Factors among Intern Nurses in Neonatal Intensive Care Unit

\begin{tabular}{|l|c|c|c|c|c|c|c|c||}
\hline \multirow{2}{*}{ Health Care System Stress Factors } & \multicolumn{9}{|c|}{$\mathbf{n = 1 4 0}$} \\
\cline { 2 - 11 } & \multicolumn{2}{|c|}{ High } & Moderate & \multicolumn{2}{c||}{ Little } & \multicolumn{3}{c||}{ None } \\
\cline { 2 - 11 } & $\mathbf{N o}$ & $\mathbf{\%}$ & $\mathbf{N o}$ & $\mathbf{\%}$ & $\mathbf{N o}$ & $\mathbf{\%}$ & No & \% \\
\hline Increase paper work. & 80 & 57.1 & 38 & 27.2 & 19 & 13.6 & 3 & 2.1 \\
\hline Routine work. & 107 & 76.4 & 33 & 23.6 & 0 & 0.0 & 0 & 0.0 \\
\hline Short breaks. & 73 & 52.1 & 39 & 27.9 & 25 & 17.9 & 3 & 2.1 \\
\hline Standing for long hours. & 63 & 45.0 & 48 & 34.3 & 24 & 17.1 & 5 & 3.6 \\
\hline Overwhelmed with hospital policy. & 57 & 40.7 & 55 & 39.3 & 25 & 17.9 & 3 & 2.1 \\
\hline $\begin{array}{l}\text { Lack of communication and support } \\
\text { from administrators. }\end{array}$ & 55 & 39.3 & 47 & 33.6 & 29 & 20.7 & 9 & 6.4 \\
\hline $\begin{array}{l}\text { View neonate death as failure in } \\
\text { nursing performance. }\end{array}$ & 64 & 45.7 & 46 & 32.9 & 27 & 19.3 & 3 & 2.1 \\
\hline Work with incompetent staff. & 68 & 48.5 & 42 & 30.0 & 25 & 17.9 & 5 & 3.6 \\
\hline Inadequate staff. & 124 & 88.6 & 0 & 0.0 & 0 & 0.0 & 16 & 11.4 \\
\hline $\begin{array}{l}\text { Lack of appreciation from } \\
\text { administrative personnel. }\end{array}$ & 62 & 44.3 & 42 & 30.0 & 29 & 20.7 & 7 & 5.0 \\
\hline
\end{tabular}


Table (7): Clinical Stress Factors among Intern Nurses in Neonatal Intensive Care Unit

\begin{tabular}{|c|c|c|c|c|c|c|c|c|}
\hline \multirow{3}{*}{ Clinical Stress Factors } & \multicolumn{8}{|c|}{$n=140$} \\
\hline & \multicolumn{2}{|c|}{ High } & \multicolumn{2}{|c|}{ Moderate } & \multicolumn{2}{|c|}{ Little } & \multicolumn{2}{|c|}{ None } \\
\hline & No & $\%$ & No & $\%$ & No & $\%$ & No & $\%$ \\
\hline $\begin{array}{l}\text { Unfamiliar with professional } \\
\text { nursing skills. }\end{array}$ & 71 & 50.7 & 43 & 30.7 & 21 & 15.0 & 5 & 3.6 \\
\hline $\begin{array}{l}\text { Fear from transmission of } \\
\text { contagious diseases. }\end{array}$ & 133 & 95.0 & 7 & 5.0 & 0 & 0.0 & 0 & 0.0 \\
\hline $\begin{array}{l}\text { Rapid changes in a neonate's } \\
\text { condition. }\end{array}$ & 78 & 55.7 & 34 & 24.3 & 25 & 17.9 & 3 & 2.1 \\
\hline $\begin{array}{l}\text { Making a mistake when giving } \\
\text { nursing care. }\end{array}$ & 68 & 48.6 & 42 & 30.0 & 23 & 16.4 & 7 & 5.0 \\
\hline $\begin{array}{l}\text { Inability to catch up with rapid } \\
\text { technology changes. }\end{array}$ & 105 & 75.0 & 35 & 25.0 & 0 & 0.0 & 0 & 0.0 \\
\hline $\begin{array}{l}\text { Provide care for many neonates at } \\
\text { the same time. }\end{array}$ & 135 & 96.4 & 5 & 3.6 & 0 & 0.0 & 0 & 0.0 \\
\hline $\begin{array}{l}\text { Provide nursing care to critically } \\
\text { ill neonates. }\end{array}$ & 126 & 90.0 & 14 & 10.0 & 0 & 0.0 & 0 & 0.0 \\
\hline $\begin{array}{l}\text { Preparing neonate for specific } \\
\text { procedure. }\end{array}$ & 62 & 44.3 & 46 & 32.8 & 27 & 19.3 & 5 & 3.6 \\
\hline $\begin{array}{l}\text { Insufficient time to complete } \\
\text { nursing tasks. }\end{array}$ & 60 & 42.9 & 44 & 31.4 & 25 & 17.9 & 11 & 7.8 \\
\hline $\begin{array}{l}\text { Too many non-nursing tasks as } \\
\text { clerical work. }\end{array}$ & 59 & 42.1 & 47 & 33.7 & 27 & 19.3 & 7 & 5.0 \\
\hline
\end{tabular}

Table (8): Environmental Stress Factors among Intern Nurses in Neonatal Intensive Care Unit

\begin{tabular}{|c|c|c|c|c|c|c|c|c|}
\hline \multirow{3}{*}{ Environmental Stress Factors } & \multicolumn{8}{|c|}{$n=140$} \\
\hline & \multicolumn{2}{|c|}{ High } & \multicolumn{2}{|c|}{ Moderate } & \multicolumn{2}{|c|}{ Little } & \multicolumn{2}{|c|}{ None } \\
\hline & No & $\%$ & No & $\%$ & No & $\%$ & No & $\%$ \\
\hline Lighting. & 70 & 50.0 & 36 & 25.7 & 25 & 17.9 & 9 & 6.4 \\
\hline Space for medical care. & 59 & 42.1 & 41 & 29.3 & 33 & 23.6 & 7 & 5.0 \\
\hline Devices, monitors and equipment. & 64 & 45.7 & 42 & 30.1 & 31 & 22.1 & 3 & 2.1 \\
\hline $\begin{array}{l}\text { Constant noises of equipment and } \\
\text { sudden alarm noise. }\end{array}$ & 105 & 75.0 & 35 & 25.0 & 0 & 0.0 & 0 & 0.0 \\
\hline Insufficient technical facilities. & 62 & 44.3 & 48 & 34.3 & 21 & 15.0 & 9 & 6.4 \\
\hline $\begin{array}{l}\text { Large number of personnel working in } \\
\text { NICU. }\end{array}$ & 53 & 37.9 & 50 & 35.7 & 26 & 18.6 & 11 & 7.8 \\
\hline Space for staff-visitor consultation. & 55 & 39.3 & 57 & 40.7 & 23 & 16.4 & 5 & 3.6 \\
\hline Overall atmosphere. & 65 & 46.5 & 41 & 29.3 & 31 & 22.1 & 3 & 2.1 \\
\hline $\begin{array}{l}\text { Being exposed to health hazards as } \\
\text { radiation }\end{array}$ & 133 & 95.0 & 4 & 2.9 & 3 & 2.1 & 0 & 0.0 \\
\hline Enclosed atmosphere. & 67 & 47.9 & 41 & 29.3 & 27 & 19.2 & 5 & 3.6 \\
\hline
\end{tabular}


Table (9): Relation between Intern Nurses' Characteristics and their Level of Stress

\begin{tabular}{|c|c|c|c|c|c|c|c|}
\hline \multirow{4}{*}{ Characteristics } & \multicolumn{6}{|c|}{$n=140$} & \multirow{4}{*}{$\begin{array}{c}\text { Test of } \\
\text { Significant } \\
\mathbf{X}^{\mathbf{2}} \\
\text { P value }\end{array}$} \\
\hline & \multicolumn{6}{|c|}{ Level of Stress } & \\
\hline & \multicolumn{2}{|c|}{$\begin{array}{c}\text { Low } \\
(0-15)\end{array}$} & \multicolumn{2}{|c|}{$\begin{array}{c}\text { Moderate } \\
(16-22)\end{array}$} & \multicolumn{2}{|c|}{$\begin{array}{c}\text { High } \\
(23-30)\end{array}$} & \\
\hline & No & $\%$ & No & $\%$ & No & $\%$ & \\
\hline \multicolumn{8}{|l|}{ Age (years) } \\
\hline$\leq 20$ & 6 & 33.3 & 10 & 55.6 & 2 & 11.1 & \multirow{2}{*}{$\begin{array}{l}X^{2}=0.926 \\
P=0.629\end{array}$} \\
\hline$>20$ & 34 & 37.9 & 63 & 51.6 & 25 & 20.5 & \\
\hline \multicolumn{8}{|l|}{ Sex } \\
\hline Male & 15 & 48.4 & 16 & 51.6 & 0 & 0.0 & \multirow{2}{*}{$\begin{array}{l}\mathrm{X}^{2}=13.153 \\
\mathrm{P}=0.001 *\end{array}$} \\
\hline Female & 25 & 22.9 & 57 & 52.3 & 27 & 24.8 & \\
\hline \multicolumn{8}{|l|}{ Marital Status } \\
\hline Single & 40 & 31.5 & 67 & 52.8 & 20 & 15.7 & \multirow{2}{*}{$\begin{array}{l}X^{2}=13.029 \\
P=0.001 *\end{array}$} \\
\hline Married & 0 & 0.0 & 6 & 46.2 & 7 & 53.8 & \\
\hline \multicolumn{8}{|l|}{ Residence } \\
\hline $\begin{array}{l}\text { Away from clinical } \\
\text { training area. }\end{array}$ & 34 & 31.5 & 51 & 47.2 & 23 & 21.3 & \multirow[t]{2}{*}{$\begin{array}{l}X^{2}=4.585 \\
P=0.101\end{array}$} \\
\hline $\begin{array}{l}\text { Near to clinical training } \\
\text { area. }\end{array}$ & 6 & 18.8 & 22 & 68.8 & 4 & 12.5 & \\
\hline \multicolumn{8}{|c|}{ Previous Experience in Private NICU } \\
\hline Yes & 19 & 33.3 & 34 & 59.6 & 4 & 7.0 & \multirow{2}{*}{$\begin{array}{l}\mathrm{X}^{2}=9.305 \\
\mathrm{P}=0.010^{*}\end{array}$} \\
\hline No & 21 & 25.3 & 39 & 47.0 & 23 & 27.7 & \\
\hline \multicolumn{8}{|l|}{ Work Schedule } \\
\hline Rotating shifts & 36 & 29.0 & 61 & 49.2 & 27 & 21.8 & \multirow{2}{*}{$\begin{array}{l}X^{2}=5.375 \\
P=0.068\end{array}$} \\
\hline Morning shift & 4 & 25.0 & 12 & 75.0 & 0 & 0.0 & \\
\hline
\end{tabular}




\section{References}

1. Mohammed M. Stress coping strategies among nurses in the intensive care units. Unpublished Master Thesis. Faculty of Nursing. Alexandria University; 2008.3.

2. Koshan M, Vaghei S. Mental Health. Tehran: Andishe Raffie Inc., 2010; 1.

3. Vinod K, Bhutani Andrew J. Stress Management and Personal Productivity: Human Relations.10thed. New Jersey: Pearson Education Inc., 2009; 322.

4. Fogaça MC, Carvalho WB, Citero VA, Nogueira-Martins LA. Factors that cause stress for physicians and nurses working in a pediatric and neonatal intensive care unit: Bibliographic review. Rev Bras Ter Intensive 2008; 20(3): 261-6.

5. Creasia J, Parker B. Conceptual Foundations: The Bridge to Professional Nursing Practice. 4th ed. United State of America: Mosby Elsevier Co., 2007; 360-445.

6. Sheikh Bahaedinzadeh A, Raei V. Nursing of Neonatal Intensive Care Unit. Tehran: Boshra Inc., 2011; 73-84.

7. Cherry B, Jacob S. Contemporary Nursing Issues: Trends and Management. St. Louis: Mosby Co., 2007; 11-9.

8. Peterson JZ. Job stress, job satisfaction and intention to leave among new nurses. Published Master Thesis. Graduate Department of Nursing Science. Toronto University; 2009.1,2.

9. Hala Y, Sayed M, Manal M. Ibrahim. Stressors among nursing staff working in intensive care unit in governmental \& non-governmental hospitals at Makkah Al-Moukarramah. J Am Sci. 2012; 8(6): 25-31.

10. Singh Ch, Sharma S, Sharma RK. Level of stress and coping strategies used by nursing interns. Nursing and Midwifery Research Journal 2011; 7(4): 152- 60 .

11. Pati D, Aiia M, Tom E, Aia H, Facha A, Barach P. Relationships between exterior views and nurse stress: An exploratory examination. Health Environments Research \& Design Journal 2008; 1(2): 27-38.

12. Mohammed FA, Gaafar YA, Abd Alkader WM. Pediatric nurses' stresses in intensive care units and its related factors. Journal of American Science 2011; 7(9): 1-12.

13. Eleni M, Theodoros C. Sources and effects of work-related stress in nursing. Health Science Journal 2010; 4(42): 210-6.

14. Harrisson M, Loiselle C Elenor J. Sullivan \& Phillip J. Effective Leadership \& Management in Nursing. 6thed. Decker: Pearson Prentice Inc., $2010 ; 302$.

15. Xianyu Y, Lambert V. Investigation of the relationships among workplace stressors, ways of coping, and the mental health of Chinese head nurses. Journal of Nursing and Health Sciences 2006; 8(3): 147-55.

16. Khan M.S, Mahmood S, Badshah A, Ali SU, Jamal Y. Prevalence of depression, anxiety and their associated factors among medical students in Karachi Pakistan. J Pak Med. Assoc. 2006; 56 (12): 583-6.

17. Hwee Ling L, Taiwanai S, Sau Lai W, Chin Peng L. Perception of stress in an intensive care unit setting among nurses working in intensive care unit and general ward. SGH Proceedings Journal 2005; 14(3): 195-202.

18. Valizadeh L, Farnam A, Zamanzadeh $\mathrm{V}$, Bafandehzendeh M. Sources of stress for nurses in neonatal intensive care 
units of east Azerbaijan province Iran. Science of Caring Journal 2012; 1(4): 245-54.

19. Cohen S, Kamarck T, Mermelstein R. A global measure of perceived stress. Journal of Health and Social Behavior 1983; 24: 385-96.

20. Barimnejad L, Azarkerdar A, Hajimiri $\mathrm{P}$, Rasouli F. The investigation of the point of view of nursing students in term five and afterward about affective factors on the development of clinical education Iranian. J. Med. Educ. 2004; 10: 64-5.

21. Sharif F, Masoumi S. A qualitative study of nursing student experiences of clinical practice. BMC Nurs. 2005; 4(6): $1-7$.

22. Omigbodun OO, Odukogbe AT, Omigbodun AO, Yusuf OB, Bella TT, Olayemi O. Stressors and psychological symptoms in students of medicine and allied health professions in Nigeria. $\mathbf{J}$ Soc. Psychiatry Psychiatr. Epidemiol. 2006:41(5): 415-21.

23. Shahsavari S, Mosallanejad L, Sobhanian S, Tehranineshat B, Faseleh M. Study the physical, spiritual and social stress related symptoms in nurses and mid-wiferies working at educational and therapeutic centers affiliated to Jahrom School of Medical Sciences. J Jahrom Med.Sch.2005; 2(2): 10-6.

24. Tully A. Stress, sources of stress and ways of coping among psychiatric nursing students. J. Psychiatr. Ment. Health Nurs. 2004; 11(1): 43-7.

25. Taghavi Larijani T, Ramezani Badr F, Khatoni A, Monjamed Z. Comparison of the sources of stress among the senior nursing and midwifery students of Tehran. Medical Sciences Universities Journal 2007; 13 (2): 61-70.

26. Chang E, Hancock K. Role stress and role ambiguity in new nursing graduates in Australia. Nursing and Health Sciences Journal 2003; 5: 155-63.

27. Yazdankhah Fard M, Pouladi S, Kamali F, Zahmatkeshan N, Mirzaei K, Akaberian S. The stressing factors in clinical education: The viewpoints of students. Iranian J. Med. Educ. 2009; 8(2): 341-50.

28. Alves SL. A study of occupational stress, scope of practice, and collaboration in nurse anesthetists practicing in anesthesia care team settings. AANA J. 2005; 73(6): 443-52.

29. Golrokh Moridi, Shahnaz Khaledi, Sina Valiee. Clinical training stress-inducing factors from the students' viewpoint: A questionnaire-based study. Nurse Education in Practice Journal 2013.1-4. http://dx.doi.org/10.1016/j.nepr.2013.08 .001

30. Morrison WE, Haas EC, Shaffner DH, Garrett ES, Fackler JC. Noise, stress, and annoyance in a pediatric intensive care unit. Crit Care Med. 2003; 31(1): 113-9. 